\title{
Hiring, Training, and Supporting Online Faculty for Higher Student Retention Efforts
}

\author{
Lisa Marie Portugal
}

This study was a phenomenological study examining the experiences of faculty teaching in an online learning environment in order to identify the factors that could produce job burnout and stress in master's programs in education. The challenges and related stress-producing factors were also explored to identify best practices for online faculty and attributes most suited for the demands and expectations required in the online teaching environment. The study's insights and findings are based on perspectives from online faculty who have been teaching in the modality for three or more years. These findings may be useful to stakeholders such as administrators, faculty mentors, faculty trainers, and faculty interested in employment in the modality so that identifiable and realistic criteria may be available upon which to base future hiring standards, employment practices, training, and decisions about teaching online. Insights about procedures and practices have been identified that may be effective in helping to develop initial training programs, faculty mentor supports, administrative decisions, and on-going faculty training. Based upon the findings, institutional leaders have information that could help identify best practices for online faculty and attributes most suited for the demands and expectations required in an online teaching environment. Institutions and administration can seek out and recruit the best possible online faculty who have the necessary skills, abilities, and characteristics required in this modality rather than hiring based merely upon academic credentials that would fail to identify specific attributes necessary for online teaching. Finally, those specific characteristics can then be applied to alleviate job burnout challenges online faculty would experience. The study will help institutional leaders (a) identify faculty earlier who will be better suited to the modality; (b) identify how to offer relevant, on-going faculty supports and training practices; and (c) prevent online faculty job burnout.

\section{INTRODUCTION}

Institutions of higher education in the United States are offering increasing numbers of online programs and courses (I. E. Allen \& Seaman, 2014). While traditional faculty members who are engaged in face-to-face lectures have recognized online teaching as a new teaching method that reaches potential university enrollees, traditional faculty continue to remain doubtful regarding the efficacy of online learning (Adams, DeFleur, \& Heald, 2007; I. E. Allen \& Seaman, 2014; Carnevale, 2007; Columbaro \& Monaghan, 2009; Mills, Yanes, \& Casebeer, 2009). The suspicion and continued distrust of faculty toward online learning have been depicted in traditional universities' preference to hire faculty who earned their degrees at traditional institutions (Adams et al., 2007; Carnevale, 2007; Columbaro \& Monaghan, 2009). This preference 
for hiring faculty who prefer traditional methods of teaching in lecture, campus-based institutions and who attained degrees from these types of institutions rather than for-profit, online degrees has the potential to result in a shortage of faculty who are best suited to online teaching.

Having online faculty, who can be most involved and fulfilled in an online environment, is important for the growth and success of institutions of higher education. However, only a small percentage of academic leaders believe that their faculty members subscribe to the legitimacy and value of the online modality (I. E. Allen \& Seaman, 2005, 2006, 2007, 2008, 2011, 2014). It is essential that online faculty be encouraged about the academic success of their online learners because the expansion of online learning requires committed and competent faculty in sufficient numbers to meet student demand. This study sought to examine the experiences of faculty in an online learning environment in order to identify the factors that can produce job burnout and stress in master's programs in education.

\section{LITERATURE REVIEW}

The primary objective of this study was to explore the experiences of faculty in an online learning environment as it related to job burnout and stress in master's programs in the discipline of education. The study also identified the teaching strategies, personal attributes, organizational skills, software competencies, and job satisfaction of faculty who taught in online master's degree programs in education to overcome the burnout problem. The literature review was done to ascertain the theoretical foundation of the topic being studied. After an exhaustive literature review search on the topic of engaged and experienced characteristics of online faculty who have taught three or more years in master's degree programs in education, it became evident that there were no studies done in this specific area. There was a dearth of literature that dealt with online faculty teaching at the master's level in the education field, which warranted this study. Key findings from the I. E. Allen and Seaman (2014) Babson Survey Research Group report on online education, Grade Level: Tracking Online Education in the United States include: (1) The percent of academic leaders rating the learning outcomes in online education as the same or supe- rior to those in face-to-face remained unchanged at $74.1 \%$; (2) Only $28.0 \%$ of academic leaders say that their faculty accept the "value and legitimacy of online education"; (3) The proportion of chief academic leaders reporting online learning is critical to their long-term strategy reached a new high of $70.8 \%$; and (4) The adoption of MOOCs (Massive Open Online Course) is reaching a plateau, only $8.0 \%$ of higher education institutions currently offer one, another $5.6 \%$ report MOOCs are in the planning stages.

\section{CONCEPTUALIZATION OF ADULT LEARNING}

To meet the educational needs and abilities of adults, Brookfield (1999) pointed to the necessity of establishing a "connectedness" to learning, encouraging adults to incorporate their previous learning and experience, to be more self-directed, and to link the curriculum to their lives and their work. Three theories of adult learning that have significantly affected higher education and the online learner include andragogy theory by Malcolm Knowles, transformative learning by Jack Mezirow, and student-centered learning by Carl Rogers.

\section{MALCOLM KNOWLES AND ANDRAGOGY THEORY}

Malcolm Knowles developed the adult learning theory known as andragogy, which explains how adults learn. Concepts such as self-directed learning, autonomy, learners being goal oriented, adults recognizing the value of learning, learning being connected to life experiences and knowledge base, learning having purpose for the adult learner, learning being self-initiated, and learning lasting longer, are basic tenets of andragogy theory (J. Green, 1998). Andragogy is highly regarded in informal, non-traditional adult education. Many nontraditional, online institutions in higher education have adopted this theory into their delivery model as well as their curriculum standards. Meaning, knowledge, and application are significant concepts theorized by the andragogy model (Knowles et al., 2005). Furthermore, this model posited that adults were self-directed in an instructional process, information had to be relevant to the adult learner, adults linked new information with previous life experiences, and the information had to be immediately usable by the learner (J. Green, 1998).

According to Smith (2002), Malcolm Knowles first learned about the "facilitator of learning" 
concept rather than the traditional "teacher" or "sage on the stage" concept when he studied under Arthur Shedlin, an associate of Carl Rogers, as a graduate student. Rogers, a clinical and educational psychologist, is best known for his work in the areas of phenomenological and humanistic theory, the concept of student-centered learning, and the notion of teacher as "facilitator" (Smith, 2002). The facilitator concept has been widely accepted as an effective model when teaching the online learner, especially in the area of distance education. The research on adult education reveals that adults have different reasons for learning and learn differently from younger individuals (Knowles et al., 2005). Generally, motivation is not problematic with the adult learner as it may be when teaching younger students. Moreover, adult learners tend to seek learning opportunities when life changes occur such as a job change or termination, divorce or marriage, a geographical change, or retirement (Smith, 2002). Adult learners prefer to direct themselves in the education process and seek out learning opportunities for specific reasons that are applicable to their own lives.

According to Gibbons and Wentworth (2001), andragogy is the explanation of how adults learn, and pedagogy is the explanation of how young people learn in elementary, junior high, secondary, and undergraduate programs, and these differences are also noted by how instructors approach content delivery. Adults have a heightened need to know why they are learning something and how it will be useful or apply to their lives, while younger learners (pedagogy theory) do not have these types of specific desires for their learning (Knowles, 1970; 1980; Knowles, Holton, \& Swanson, 2005; 1998; Pew, 2007). According to Merriam, Caffarella, and Baumgartner (2007), "The assumptions regarding an adult's self-concept, experience, readiness to learn, problem-centered focus, and internal motivation all have some intuitive validity, making andragogy popular with practitioners in many fields" (p. 104). Knowles (1980) argued that there are six assumptions regarding adult learning and he believed these assumptions were paramount in how one should create adult learning programs.

Other models of adult learning that are similar to Knowles's andragogy theory are "McClusky's theory of margin (which actually predates andragogy)," "Illeris's three dimensions of learning," and
“Jarvis's learning process" (Merriam, Caffarella, \& Baumgartner, 2007, p. 93). Knowles's theory emerged at another time in circumstances far apart from online learning.

\section{SUMMARY}

Online learning communities and modalities offer the online learner flexibility, autonomy, and self-direction. The three learning theories highlighted relate well to these concepts, and coursework designed for the online learner is well accommodated by each of these theories. Higher education pursuit via an online modality is an excellent equalizer because physical appearance, age, race, weight, clothing, disability, and the prejudices, biases, and assumptions of others do not necessarily play as large a role as they would if one were sitting in a physical classroom.

Although the three theories of adult learning discussed in this chapter have significantly defined the field of adult education, "no single theory of adult learning has emerged to unify the field. Rather, there are a number of theories, models, and frameworks, each of which attempts to capture some aspect of adult learning" (Merriam et al., 2007, p. 103). Knowles, Mezirow, and Rogers are known as humanistic theorists, and each wrote extensively on the notion of self-directed learning, which is a concept well-suited to the development of modalities specifically created for the online learner. Facilitators, program developers, and curriculum writers who incorporate adult learning theories such as andragogy, transformative learning, and student-centered learning will find that their online programs will benefit the online learner immeasurably.

According to Merriam et al., (2007), a humanistic orientation to learning emphasizes human nature, human potential, human emotions, and affect (p. 294). Choice, motivation, and responsibility are necessary factors related to the online learning process. The role of prior knowledge and experiential learning must be incorporated into any online learning classroom environment. These factors, when allowed to manifest in an online environment, may significantly affect the learning experiences of the online learner in positive ways. The study provides insight into online faculty burnout and methods and strategies faculty use in their classrooms. Previous studies have not interviewed 
online faculty in master's programs in the college of education.

\section{RESEARCH QUESTIONS}

1. Why do faculty choose to facilitate an online course(s)?

2. How do faculty prepare for this assignment?

3. What do faculty find are the major differences between lecture/discussion face-toface instruction and online learning?

4. In what ways has facilitating an online course been both rewarding and challenging?

5. What do faculty find to be the most challenging aspects of facilitating an online course?

\section{METHODOLOGY}

The purpose of this phenomenological qualitative research study was to identify the teaching strategies, personal attributes, organizational skills, software competencies, and job satisfaction of faculty who teach in online master's degree programs in education. Qualitative data were gathered through semi-structured, open-ended interview questions with 12 online faculty to gain insights and a detailed view of online faculty and their teaching strategies, personal attributes, organizational skills, and job satisfaction. This qualitative research used a modified van Kaam method developed by Moustakas (1994). The modified Kaam method was based upon recorded and transcribed interviews using semi-structured questions to capture the lived experiences of online faculty.

\section{SAMPLING PROCEDURE}

The study used a purposeful sampling method for understanding and exploring specific purposes and judgments of a select group or case of individuals who had experienced the same phenomenon (Fitzpatrick, Sanders, \& Worthen, 2004; Lincoln \& Guba, 1985). Participants were chosen based upon the following inclusion criteria:

1. Taught at least four online courses within a year;

2. Taught for three or more years; and

3. Taught in a master's degree program in education.

In order to recruit participants for the study, the researcher used purposeful sampling by inviting online faculty to participate such as colleagues and acquaintances based upon years of experience in the field of online teaching in the college of education at many institutions. Those to be interviewed were from many different settings, were nominated by those that knew their online work, and were responding as individuals not faculty at a specific institution. In fact, some did not have any institutional affiliation whatsoever.

\section{DATA COLLECTION}

The factors included the need for data from subject matter experts based upon lived experiences, access to a representative population, and varied perspectives from diverse participants. Unstructured observational data in different venues as a participant observer or non-participant observer were not available, and this precluded the opportunity to take field notes or to record data to inform the research. The most appropriate and available data collection method to achieve data validity and reliability in the target population frame was the semi-structured interview (Elliott, 2005).

This research study utilized telephone interviews to capture a wider range of participants in terms of geographic locations. Telephone interviews, however, permitted less time to collect data, but allowed better access to research participants, especially for those in different geographic locations. Thus, this research study utilized telephone interviews. Participants were informed that the conversation would be recorded and would be transcribed for data analysis. The interviews lasted approximately 20 to 30 minutes, and interviews took place only once.

The researcher invited online faculty such as colleagues and acquaintances to participate based upon their years of experience in the field of online teaching in the college of education at various institutions. Instructions as to how to participate in the study were made available. Interested participants received an overview of the study. If their qualifications matched the criteria considered in this study, they were included as potential participants. All potential participants were contacted to arrange for telephone interviews. During the interview process, participants were informed that audio tapes were to be employed to ensure that their responses could be transcribed appropriately. A transcribed copy was 
also provided to each participant for approval after the interview process. The data collection process ended when the researcher received the approved copy of the transcribed interview. After that, the data was inputted to the NVivo(C) qualitative analysis software program for data analysis.

\section{DATA ANALYSIS}

The study was analyzed using triangulation techniques, which included the use of multiple data collection methods, analysts, data sources, or theories as collaborative evidence for the validity of standard qualitative research findings (Gall, Gall, \& Borg, 2003, p. 640). For the study, multiple methods employed included qualitative analysis as well as the use of multiple analysts in the development of the qualitative component.

The triangulation method condensed, clustered, and sorted the data by implementing the following steps:

Step \#1: Interview participants were selected in the following order: (a) three participants from a public university, (b) three participants from a private university, (c) three participants from a forprofit university, and (d) three participants from a research 1 university to triangulate how participants from four different types of institutions respond to the qualitative questions.

Step \#2: Interview participants via phone with qualitative questions.

Step \#3: Transcribe and give responses to the participants for review and approval.

Step \#4: Collaborate with outside evaluator on the study to evaluate the transcriptions. Outside evaluator will collaborate to identify and analyze meaning units and assign themes (Creswell, 1998).

The phone interviews lasted approximately one hour for each participant. In addition, all participants had a great deal of information and experiences to share that was similar regardless of the categories they were in as stated above.

\section{DATA ANALYSIS AND RESULTS}

The result of the analysis yielded the following thematic categories and thematic subcategories: (a) category 1: factors that drive faculty to facilitate an online course; (b) thematic subcategory 1: challenges that were overcome by online instructors; (c) thematic subcategory 2: effective teaching- learning practices in an online learning environment; (d) thematic category 2: faculty preparation for online teaching assignment; (e) thematic subcategory 3: personal attributes of instructors in an online learning; (f) thematic category 3: perceived differences between lecture/discussion face-toface instruction and online teaching; (g) thematic category 4: elements of online teaching that reward online instructors; and (h) thematic category 5: challenging elements in online course facilitation. In the analysis of the first thematic category, two subcategories emerged: (a) challenges that were overcome by online instructors, and (b) effective teaching-learning practices in an online learning environment.

\section{DISCUSSION OF THE RESULTS}

The thematic categories of the present study were the lived experiences of the online instructors with regards to teaching in an online environment. The majority of these participants had many years of teaching experience in a traditional classroom environment before joining the pool of online instructors. These faculty members were specifically exposed to various traditional and progressive teaching methods and strategies and had worked with diverse adult and minor learners extensively before teaching online. These teaching experiences gave them advantages in taking classes via the online learning environment. In fact, these experiences have become significant factors driving their decisions to handle online classes.

While the participants had several advantages, they also indicated several challenges to overcome before they became generally satisfied with online teaching. The theme ability to cope with the challenges in an online teaching-learning environment arose from this observation. The inherent challenges of online teaching are manageable among instructors with wide teaching experience and innate time-management ability. The challenges to becoming effective in online teaching included the following: (a) management of students' behaviors, (b) the innate limitations of online learning, (c) learning online technologies, (d) management in responding to multiple e-mails, and (e) individualized teaching strategies. These challenges among others were overcome even without instruction from the administrators.

Managing student behaviors in relationship to 
student codes of conduct involves helping students understand how to address peers and professor in a professional, academic tone in all activities and correspondence in the classroom. This may include posting specific announcements regarding the issue, modeling an academic, professional tone in all materials the faculty present in the classroom, and quickly and professionally addressing any misbehavior or unprofessional tone that may be presented by students.

Innate limitations of online learning include the fact that faculty cannot meet with learners face to face to explain concepts, lecture material, or answer questions in person. For some students, this may be a challenge that online faculty must address in other ways. Faculty can address this by being present daily in their classrooms, being present before and after typical working hours of 8am to $5 \mathrm{pm}$, being present in the classroom on weekends and nights, answering questions in detail within 24 hours, presenting various ways to contact faculty via e-mail, phone, social media, classroom chat room, faculty website, instant messaging, creating questions to the instructor section or links within the classroom, and posting answers to common questions.

Learning online technologies involves learning new software and programs quickly and effectively so that there is little to no down time in the online classroom. Faculty are required to learn new online technologies on a regular and consistent basis. Online coursework often requires changes to the curriculum and systems need to be altered, removed, changed, and newly created. Faculty need to be able to learn these new skills as quickly and effectively as possible so that students and teaching ability are not negatively impacted. Learning online technologies quickly and adeptly is a fundamental and significant skill for faculty to possess.

Management in responding to multiple e-mails is required by online faculty. Most universities with online coursework require faculty to respond to students within 24 hours. Faculty are required to manage student e-mails and questions with individualized attention and in a timely manner. Finding ways to do this on a daily basis is necessary for faculty.

Individualized teaching strategies may involve faculty using progressive teaching strategies that address various learning styles with significant, specific feedback to each learner that is unique to each learner's needs. A one-size-fits-all approach to teaching does not address individualized teaching strategies. Faculty should be addressing students on an individual basis, meeting the student where he or she is, and working toward bringing each student to a higher level. This approach requires that faculty respond to each student according to his or her needs rather than using a cut-and-pastethe-same-information-to-all-students approach. All correspondence to each student should be created uniquely for each student based upon students' comments, assignment submissions, e-mails, questions, and so on.

Among the driving forces that attracted retention among the online instructors was the flexible time that is inherent in the online teaching environment. The instructors are able to travel without compromising their responsibilities with students. In addition, working parents prefer to teach online because it allows them to perform their familial roles while practicing their teaching profession. Although faculty have specific deadlines for posting, grading, and answering student questions, teaching online can take place 24/7 and asynchronously. This allows faculty the opportunity to schedule other personal and professional duties as they chose. Online faculty are not micromanaged in a physical office or a campus-based classroom on a Monday through Friday, 8 a.m. to 5 p.m. schedule. For example, if faculty must post grades every week by Wednesday, midnight Central time, this can be done days before the deadline, on the weekend, or hours before the deadline. Faculty can manage other personal and professional duties however and whenever they choose as long as that deadline is met each week. This allows faculty the opportunity to create flexibility in their lifestyles and other commitments and duties however they choose as long as university deadlines and expectations are met. An example of flexibility is that faculty can be present and post in online classrooms for fifteen minutes daily and yet meet weekly deadlines and work for many hours on one or two days of the week.

Another example of flexibility is that faculty can be present and producing in the online classroom while completing other personal and professional computer or Internet research-related tasks. Depending upon how adept faculty are at multi- 
tasking, they can be present in the online classroom while pursuing these other activities simultaneously. Another example be may be where faculty can be producing and present in multiple online classrooms simultaneously. In addition, faculty can check into several classes within the same halfhour or hour timeframe without the constraints of physical buildings, walls, or walking great distances across campus. This may not be as easily accomplished in campus-based courses as instructors can only be present in one place at one time. Online faculty can be in many online classrooms simultaneously while producing quality work depending upon the technological savvy and time management skills they may possess.

Other examples of flexibility include parents working from home while caring for and managing children and family commitments. Faculty can travel for personal or professional reasons and with an Internet connection they are able to be present in the online classroom. Faculty can work for multiple universities in an online capacity. Faculty can have full-time, ground-based, 8 am to $5 \mathrm{pm}$ employment and also teach several online classes. Many online faculty in the College of Education are working parents who teach full-time in public K-12, campus-based schools and work for a variety of universities in an online teaching capacity. Some online faculty teach campus-based university courses in addition to their online courses. Time management is left to faculty to handle as they see fit rather than being micromanaged by the university as long as faculty expectations and deadlines are met.

Other factors faculty considered important in their decisions to teach online were the reduction of the physical stress from the time spent driving to and from their respective universities and exposure to new teaching pedagogy. These factors contributed to the positive work satisfaction of online instructors in this study.

While the participants are professionally and technically prepared for online teaching, they noted the recruitment process as a crucial stage that determines the success of universities in offering online courses. These participants articulated that online instructors should have personal characteristics that are aligned with the demands of online teaching, ability to manage students' behaviors, and knowledge in teaching styles that are appropriate to the diverse needs of online students. These charac- teristics of online instructors include (a) good organization skills, (b) effective time management, (c) positive work attitude and behavior, (d) comfort in an online learning environment, (e) technological competence, and (f) flexibility in dealing with students' needs. Instructors with these characteristics can be identified via new faculty training programs such as an online faculty training classroom where new faculty are required to perform specific tasks. In addition, reviewing faculty resumes and asking specific interview questions related to experience with the management of students' behaviors, online learning and teaching, learning online technologies, time management, working with students in a timely manner, and individualized teaching strategies should be considered in the hiring process. Meeting criteria in these areas and performing according to specific expectations in an online training classroom would be first steps to identifying online faculty candidates. Peer monitoring, monitoring in the first class one is assigned to teach, and monitoring over a yearly basis would be further steps in identifying faculty who could perform at expected and required levels.

The required attributes of an online instructor were based on the pedagogical differences between face-to-face instruction and online teaching, where the former emphasizes a less individualized approach to learning than the latter. The participants have cited that with online teaching, instructors are required to monitor and evaluate each student's learning progress and behavior in the online classroom. Unlike in traditional classrooms, teaching online requires the instructor to post, review, and synthesize the online discussion as means to encourage students' participation in the online classroom.

In addition, the nature of the online classroom requires more time in the preparation of instructional materials and evaluation of students' performance than face-to-face instruction. The online instructors must be sensitive to the difficulties students may encounter with online learning such that they can appropriately design instructional materials that are effective for students who may experience difficulties. Moreover, online instruction imposes urgency in reviewing and providing feedback to keep the online discussion and coursework active. Based on these responsibilities and work expectations, online instructors must have competency in written instruction. 
The thematic category elements of online teaching that reward online instructors reiterated the factors that motivate educators in teaching online. The perceived rewards among the educators involved in the study were (a) continuing enhancement of technological competence, (b) meeting of personal and professional satisfaction, and (c) opportunity for new learning and improvement. These themes were consistent across the responses of the participants.

While these elements focus on the individual needs of the educators in an online learning environment, the degree of academic support from the school administration has also been examined. Accordingly, online course facilitation needs appropriate guidelines, policies, and procedures to protect the integrity of education and the online instructors. In this study, job burnout and stress were associated with decisions of the administration to favor students' unjust complaints over the online faculty.

\section{DISCUSSION OF THE RESULTS IN RELATION TO THE LITERATURE}

While the present study also aims to understand the job burnout and stress among online faculty in relation to their responsibilities in teaching the students enrolled in a master's education program, the researcher was unable to collect this information from faculty who have several years of teaching experience in both traditional and online classrooms. The faculty who participated in the present study denied experiencing job burnout and in fact suggested that online teaching offers them satisfaction, as they can practice their teaching profession while performing their familial roles. The perceived work satisfaction motivated them to learn available technology so they can further enrich their teaching strategies and become effective in teaching students with diverse learning needs.

In effect, their years of online teaching gave them expertise in the management of online discussion as well as the management of students' behavior, even without guidance from online classroom administrators. For instance, one participant claimed that as she earned experience in teaching, she adopted a random selection of students' online postings for evaluation and feedback. From the experiences of the faculty, it was evident that fit and role ambiguity are related to years of experience
(Rubino, Luksyte, Perry, \& Volpone, 2009). This means that as years of teaching experience of faculty increase, fitness for the work environment increases while role ambiguity decreases (Rubino et al., 2009).

This level of comfort in the work environment is evident in the deep concern faculties have demonstrated to their students. Within the online learning environment, the instructors possess higher commitment in terms of providing individualized teaching and mentoring, particularly to those students who have learning difficulties as well as difficulties in the use of technology. Unlike traditional classrooms, the online instructors are committed to ensure that presentation materials are effective for self-learning. The inherent difficulty of self-learning has been considered by the online instructors as shown in their commitment to respond to students' e-mails immediately. The urgency of responding to e-mails was considered an important strategy in sustaining the interest of students in learning the required online tasks. In many cases, instructors respond to students outside typical face-to-face class schedules to clarify learning points that are difficult to understand in the online environment (Beer et al., 2005; Bocchi et al., 2004; Gaytan \& McEwen, 2007; Oliver, 2004).

The challenges noted in the empirical research, such as work-related demands, necessary work adjustments, methods in managing online discussion boards, students' behavior, inactive discussions, proper netiquette in classroom, ensuring quality participation, and their responsibilities as instructors have been confirmed in this research (Betts, 2008; Claybon, 2008; Dolan, 2011); however, these challenges are not the factors that provide stress and job burnout, which can subsequently be the reasons for faculty resignation (Claybon, 2008; Perry, 2008; Wiesenmayer et al., 2008). The elements that contribute to job burnout and stress among online faculty who have been teaching for several years are their inability to handle the behavior of students who take for granted their online course requirements, the demands of students for higher grades without making extra efforts, administrators who take the side of students who complain unjustly, and administrators who compromise quality education to attract and retain students. These stressors are particularly experienced by online faculty from private for-profit academic institutions, who avoid 
arbitration due to fear of losing their jobs (Beam et al., 2003; Rubino et al., 2009).

In the attempt to manage an active online discussion while avoiding conflict with students, online instructors ensure that grading rubrics are set, clarified, and agreed by the students enrolled in the course. Based on this agreement, the instructors evaluate the students' performance based on the agreed rubrics. All 12 participants interviewed in this study discussed how rubrics also serve as the instructors' monitoring and evaluation tool concerning the achievement of the learning course objectives (Beer et al., 2005; Bocchi et al., 2004; Gaytan \& McEwen, 2007; Oliver, 2004).

In this study, four general factors motivated online faculty in their decisions to teach in an online learning environment. The factors were (a) the ability to cope with the challenges in an online learning environment, (b) being able to balance familial roles and professional practice without getting physical stress, (c) online teaching provides professional and personal satisfaction, and (d) perceptions that the online environment offers a new perspective in teaching students. This information further implies that these intrinsic motivations were not evident among faculty in traditional learning environments. In the light of the results of the present study, the researcher affirmed the findings of the earlier studies that concluded that there was job burnout and stress among online instructors (Beam et al., 2003; Betts, 2008; Claybon, 2008; Dolan, 2011; Iiacqua et al., 1995; McLean, 2005; Oliver, 2004; Perry, 2008; Pines \& Aronson, 1989).

However, unlike the factors that contribute to job burnout and stress as identified in past research (e.g., Bruner, 2007; McLean, 2006) the present study posits that the nature of online teaching and the job responsibilities of online instructors do not significantly affect their commitment to work. The participants of the study have claimed that the perceived attitude of students concerning online instruction as "diploma mill course work" and the tolerance of the online administrators to this perception in exchange for student retention and enrollment are factors that affect the online instructors' motivation and job commitment.

\section{IMPLICATION OF THE RESULTS FOR PRACTICE}

The results of the present study provided em- pirical information on the job burnout and stress of online instructors in the master's education program in American universities. Literature has been scarce in this area since online distance education was introduced in higher education. Specifically, the results provided the perspectives of online instructors who have teaching experience in nontraditional, for-profit universities that most often serviced adult, non-traditional, and at-risk learners. New faculty may benefit from this study because participants revealed various job actions, habits, expectations, traits, daily routines, job stressors, and burnout challenges that are specific to online instruction. This study also revealed various differences regarding teaching for public, private, for-profit, and research 1 institutions that compare and contrast how faculty are expected to manage student issues, challenges to authority, and negative student behaviors. Furthermore, many online institutions enroll at-risk, non-traditional, adult learners who may have learning difficulties and present challenges to instruction that require specific facilitation methods. Not all faculty may be willing or equipped to handle teaching online or the demands required in for-profit institutions. In addition, this study revealed the technological demands, individualized teaching, and feedback on student requirements in addition to the inherent challenges of online instruction that faculty are required to address and manage effectively. Finally, faculty expectations for grading deadlines and a 24-hour turnaround response to all student questions and inquiries may be challenging to faculty who are accustomed to the traditional, campusbased environment.

The most relevant research findings of the present study to educational practices was on the selection of online instructors with personal attributes that are aligned with the online teaching environment. The university administrators who intend to improve the delivery of quality education through online education must emphasize the development of these attributes to their hired online instructors. Other than providing training on the use of software and other related technology, administrators of online instructors may also consider the development of value-based training and development specifically in honing their patience and diligence in mentoring students with learning difficulties.

Regular monitoring of faculty during the inter- 
view stage where faculty are required to complete a mock online training class, the first class assignment, and annual peer-mentoring and monitoring evaluations would be effective. In addition, faculty supports such as faculty chat rooms, on-going training and mentoring in areas such as technology, software, classroom facilitation techniques, and research support in all areas of online instruction would be beneficial. Faculty could benefit from peer-mentoring and administration support where questions, problems, and solutions can be addressed effectively and without fear of dismissal. Experienced online faculty can provide additional support to new faculty in all areas of instruction and student management via e-mail, faculty chat rooms, peer-mentoring, and sharing of research and effective facilitation strategies. Administrators could create peer-mentoring groups where an experienced faculty member manages a group of less experienced faculty so that a regular contact for guidance is established with open communication channels.

Taking into account themes that have been identified in this study, online coordinators and higher education leadership have a framework and a basis of knowledge and information to aid in their hiring practices and support of online faculty. The participants in this study can offer insight into hiring practices and support of online faculty as they each (a) had vast teaching experiences, (b) had deep knowledge and expertise in teaching, (c) were skillful in the management of individual learning difficulties, and (d) were skillful in teaching atrisk learners. Identifying and supporting faculty who can specifically work with individual learning difficulties and at-risk learners is a major factor discussed by the participants. Having patience, diligence, and exposure to various traditional and progressive teaching methods and strategies was also common with these participants. In addition, working with diverse adult and minor learners extensively before teaching online was common. Based upon these factors, online coordinators and higher education leadership should understand the importance of hiring and supporting online faculty who have these traits, abilities, skills, and experiences.

Furthermore, faculty who can effectively manage challenging student behaviors, individualized feedback, the inherent challenges of online teach- ing, and time management seem to do best in an online environment. Hiring, training, and supporting new faculty in these areas is essential and may relieve stress, job burnout, attrition of faculty, and attrition of students.

\section{RECOMMENDATIONS FOR FURTHER RESEARCH}

While the results of the present study are compelling regarding job burnout and stress among instructors in relation to their teaching careers in an online learning environment, the researcher recommends further research on the lived experiences of newly hired online instructors who have a maximum of at least two years teaching experience either in traditional and online learning environment. The contribution of this recommended research is that it will further explore the challenges and coping mechanisms of these newly hired online instructors with regards to the identified issues of the expert online instructors. With this research, attrition of newly hired online instructors can be resolved.

With regards to integration of technology and mentoring of its use to online instructors, past research has shown the value of teachers' attitudes toward technology in general and the use of this technology in effective online instruction (Bahr et al., 2004; Helton \& Helton, 2005). This conclusion has been reiterated in the present study; however, the process of technology integration to instructors' systems of work has not been explored. The perspective emerging from the interview data was that online instructors are already knowledgeable, if not experts, on information technology, including the use of software for the improvement of online instruction materials. In this regard, further research can be done concerning online instructors' processes of acquiring knowledge and skills of information technology. This future research can further provide effective strategies in molding a pool of instructors who are receptive and eager to integrate technology into their curriculum more than required by school administrators (Grove et al., 2004; Tallent-Runnels et al., 2006).

Furthermore, regardless of age, online instructors have similar views concerning the relationship of use of technology and ease of teaching (Bruner, 2007). However, younger instructors are more adept in the use of technology when compared to instructors who may have longer teaching careers 
(Beam et al., 2003; Iiacqua et al., 1995; Terpstra \& Honoree, 2004). In this case, a study comparing the strengths and weaknesses of younger and older age cohorts may need to be done to understand the behavior, stress, and job burnout of online instructors in relation to use of technology and effective instruction better.

\section{CONCLUSION}

This study is particularly important among universities who envision hiring, supporting, and training online faculty who are best equipped to manage the rigors of the online environment and adult, at-risk learners who may have challenging behaviors and learning difficulties effectively. The thematic categories used in understanding effective online classroom instruction as well as the constraints in the achievement of quality online education can guide administrators in the development of professional training exercises for their regular and newly hired online instructors to learn and adopt effective strategies in reaching these at-risk students. Not all faculty may have the attributes and innate skills necessary to be effective, successful, and satisfied teaching in an online environment. Online coordinators and higher education administrators have a specific challenge in identifying faculty who are best suited for this type of employment. Furthermore, once faculty are identified, supporting and training the newly hired present additional challenges. The strengths that experienced online faculty bring to this form of learning have been identified as major themes discussed by all 12 participants in the areas where one $100 \%$ consensus was present quite often.

Based upon the overwhelming common themes reported by all participants, it is evident that online coordinators and higher education administrators can find specific areas of importance in relationship to hiring practices, support, and training for new and currently employed online faculty support, and training for new and currently employed online faculty.

\section{ACKNOWLEDGMENTS}

Portions of this article appear in the book Successful online faculty principles and best practices: Identifiable criteria for employment practices, hiring standards, training, and leadership decisions. Copyright 2015 by Dr. Lisa Marie Portugal and Scholars' Press is a trademark of OmniScriptum GmbH \& Co. KG. Saarbrücken, Germany. Reprinted by permission of the publisher and author.

\section{REFERENCES}

Allen, I. E., \& Seaman, J. (2007, October). Online nation: Five years of growth in online learning. Needham, MA: Sloan Consortium.

Allen, I. E., \& Seaman, J. (2008). Staying the courses: Online education in the United States, 2008. Needham, MA: Sloan Consortium.

Allen, I. E., \& Seaman, J. (2011). Going the distance: Online education in the United States, 2011. Needham, MA: Sloan Consortium.

Allen, I. E., \& Seaman, J. (2014, February). Grade level: Tracking online education in the United States. Needham, MA: Sloan Consortium.

Bahr, D. L., Shaha, S. H., \& Farnsworth, B. J. (2004). Preparing tomorrow's teachers to use technology: Attitudinal impacts of technology-supported field experience on preservice teacher candidates. Journal of Instructional Psychology, 31(2), 88-97.

Beam, R. A., Kim, E., \& Voakes, P. S. (2003, Winter). Technologyinduced stressors, job satisfaction and workplace exhaustion among journalism and mass communication faculty. Journalism \& Mass Communication Educator, 57(4), 335.

Beer, M., Slack, F., \& Armitt, G. (2005). Collaboration and teamwork: Immersion and presence in an online learning environment. Information Systems Frontiers, 7(1), 27-37.

Berg, B. (2004). Qualitative research methods for the social sciences (5th ed.). Needham Heights, NY: Allyn and Bacon.

Betts, K. S. (2008, Spring). Financial bottom line: Estimating the cost of faculty/adjunct turnover and attrition for online programs. Online Journal of Distance Learning Administration, 11(1). Retrieved from http://www.westga.edu/ distance/ojdla/ spring111/betts111.html 
Bocchi, J., Eastman, J. K., \& Swift, C. O. (2004). Retaining the online learner: Profile of students in an online MBA program and implications for teaching them. Journal of Education for Business, 79(4), 245-253.

Brockhoff, K. (1975). The performance of forecasting groups in computer dialogue and face-to-face discussions. In $\mathrm{H}$. Linstone \& M. Turoff (Eds.), The Delphi method: Techniques and applications (pp. 291-321). Reading, MA: Addison-Wesley.

Bruner, J. (2007). Factors motivating and inhibiting faculty in offering their courses via distance education. Online Journal of Distance Learning Administration, 10(2). Retrieved from http://www.westga.edu/ distance/ojdla/summer102/bruner102.htm

Cassell, C., \& Symon, G. (2004). Essential guide to qualitative methods in organizational research. London, UK: Sage.

Cercone, K. (2008). Characteristics of adult learners with implications for online learning design. AACE Journal, 16(2), 137-159.

Claybon, L. P. (2008). A case study of burnout experiences of faculty who teach online graduate courses. Available from ProQuest Dissertations and Theses database. (UMI No. AAT 3303736)

Creswell, J. (1998). Qualitative inquiry and research design: Choosing among five traditions. Thousand Oaks, CA: Sage.

Dolan, V. L. B. (2011, February). The isolation of online adjunct faculty and its impact on their performance. International Review of Research in Open and Distance Learning, 12(2). Retrieved from http://www.irrodl.org/index.php/irrodl/article/ view/793

Elliott, J. (2005). Using narrative in social research: Qualitative and quantitative approaches. Thousand Oaks, CA: Sage.

Fitzpatrick, J. L., Sanders, J. R., \& Worthen, B. R. (2004). Program evaluation: Alternative approaches and practical guidelines (3rd ed.). Boston, MA: Pearson Education.

Gall, M. D., Gall, J. P., \& Borg, W. R. (2003). Educational research: An introduction (7th ed.). Boston, MA: Pearson Education.

Gaytan, J., \& McEwen, B. C. (2007). Effective online instructional and assessment strategies. American Journal of Distance Education, 21(3), 117-132.

Grove, K., Strudler, N., \& Odell, S. (2004). Mentoring toward technology use: Cooperating teacher practice in supporting student teachers. Journal of Research on Technology in Education, 37(1), 85-109.
Helton, C., \& Helton, C. (2005). Mentoring distance learning faculty from a distance. Paper presented at the Society for Information Technology and Teacher Education International Conference, Chesapeake, VA.

liacqua, J. A., Schumacher, P., \& Li, H. C. (1995, Fall). Factors contributing to job satisfaction in higher education. Education, 116(1), 51.

Knowles, M. S. (1970). The modern practice of adult education: Andragogy versus pedagogy. The Association Press, 291 Broadway, New York, N.Y.

Knowles, M. S., Holton, E. F., \& Swanson, R. A. (2005). The adult learner: The definitive classic in adult education and human resource development (6th ed.). Burlington, MA: Elsevier.

Knowles, M. S. (1980). The modern practice of adult education. Chicago, IL: Follet.

Knowles, M. S., Holton, E. F., \& Swanson, R. A. (1998). The adult learner (5th ed.). Houston, TX: Gulf.

Lincoln, Y. S., \& Guba, E. G. (1985). Naturalistic inquiry. Newbury Park, CA: Sage.

Marshall, C., \& Rossman, G. (1999) Designing qualitative research (3rd ed.). Thousand Oaks, CA: Sage.

McLean, J. (2006). Forgotten faculty: Stress and job satisfaction among distance educators. Online Journal of Distance Learning Administration, 9(2). Retrieved from http://www.westga. edu/ distance/ojdla/summer92/mclean92.htm

Merriam, S., Baumgartner, L., \& Caffarella, R. (2007). Learning in Adulthood: A comprehensive guide. San Francisco: JosseyBass.

Moustakas, C. (1994). Phenomenological research methods. Thousand Oaks, CA: Sage.

Oliver, C. (2004). Teaching at a distance: The online faculty work environment. unpublished dissertation, The City University of New York, New York.

Perry, A. (2008). The perception of online faculty as it relates to compelling presence in the online environment (Doctoral dissertation). Available from ProQuest Dissertations and Theses database. (UMI No. AAT 3307286)

Pew, S. (2007). Andragogy and pedagogy as foundational theory for student motivation in higher education. InSight: A Collection of Faculty Scholarship. Retrieved from http://insightjournal.net/Volume2/Andragogy $\% 20$ and $\% 20$ Pedagogy $\% 20$ as $\% 20$ Foundational $\% 20$ Theory $\% 2$ for $\% 20$ Student $\% 20$ Motivation\%20in\%20Higher\%20Education.pdf 
Pines, A., \& Aronson, E. (1989). Career burnout: Causes and cures. Glencoe, IL: Free Press.

Portugal, L. M. (2015). Successful online faculty principles and best practices: Identifiable criteria for employment practices, hiring standards, training, and leadership decisions. Scholars' Press is a trademark of OmniScriptum GmbH \& Co. KG. Saarbrücken, Germany.

Rubino, C., Luksyte, A., Perry, S. J., \& Volpone, S. D. (2009). How do stressors lead to burnout? The mediating role of motivation. Journal of Occupational Health Psychology, 14(3), 289-304.

Tallent-Runnels, M. K., Thomas, J. A., Lan, W. Y., Cooper, S., Ahern, T. C., Shaw, S. M., \& Liu, X. (2006). Teaching courses online: A review of the research. Review of Educational Research, 76(1), 93.

Terpstra, D. E., \& Honoree, A. L. (2004, Spring). Job satisfaction and pay satisfaction levels of university faculty by discipline type and by geographic region. Education, 124(3), 528-540.

Wiesenmayer, R., Kupczynski, L., \& Ice, P. (2008, Winter). The role of technical support and pedagogical guidance provided to faculty in online programs: Considerations for higher education administrators. Online Journal of Distance Learning Administration, 11(4). Retrieved from http://www.westga. edu/ distance/ojdla/winter114/wiesenmayer114.html

\section{APPENDIX A}

\section{INTERVIEW QUESTIONS}

Research Question \#1

1. Why do faculty choose to facilitate an online course(s)?

Interview Questions \#1

a. What work-related practices do you use as you teach online that may be different from what you are used to doing in a regular brick and mortar classroom?

b. What adjustments have you made, if any, to be successful as an instructor in the online classroom?

c. What methods do you use to manage your online discussion boards?

d. How do you manage a dominating, rude, or disrespectful student?

e. How do you manage a discussion that has become inactive? f. What ideas do you have for maintaining proper netiquette in the classroom?

g. What strategies do you use in the online classroom to encourage and ensure quality participation in threaded discussions?

$h$. What is your interpretation of your responsibility as an online instructor?

Research Question \#2

2. How do faculty prepare for this assignment?

Interview Questions \#2

a. What personal attributes do you have that you believe are necessary for teaching online?

b. How do you handle possible procrastination issues?

c. How do you handle possible job burnout issues?

d. How does your teaching style and/or philosophy fit in with the requirements and demands of online instruction?

e. How do you feel about the notion of the "student as customer" philosophy that has been adopted by many online institutions in higher education?

f. How do you handle students who challenge your facilitation style, methods, and strategies?

Research Question \#3

3 . What do faculty find are the major differences between lecture/discussion face to face instruction and online learning?

Interview Questions \#3

a. What are your administrative and clerical skills that you believe are necessary for teaching online?

b. What methods do you use for time management?

c. How do you use these methods to successfully facilitate online classes?

Research Question \#4

4. In what ways has facilitating an online course been both rewarding and challenging?

a. How well do you use the software required for online teaching?

Research Question \#5

5. What have faculty found to be the most challenging aspects of facilitating an online course?

Interview Questions \#5

a. How satisfied are you with online teaching?

b. What are your motivators to teach online? 
c. How do you feel about your personal accomplishments as an online educator?

\section{Author Biography}

Dr. Lisa Marie Portugal holds a PhD in Leadership for Higher Education. She instructs undergraduate, graduate and doctoral coursework in the College of Education for various institutions. Her expertise includes student engagement and success, adult learning theory, best practices in online learning, faculty and student retention, emerging technologies, non-traditional and at-risk learners, hiring practices, and faculty burn-out. Dr. Portugal has written an academic book, published extensive peer-reviewed scholarly articles, and she continues to mentor others how to reach their personal and professional goals, teach online coursework worldwide, research, write and publish. 


\title{
Conspicuous Strategies in Teaching Expressive Writing: A Quantitative Study Comparing Two Approaches to Process Writing
}

\author{
Jennifer Fontenot I Karen J. Carney I Kay Hansen
}

A process-writing approach $(B W)$ with novel concepts was developed by the authors to teach writing to elementary-level students. They believed the BW approach was effective but was particularly effective for special-needs students. Consequently, they decided to quantitatively test these assertions. Instead of testing students taught using the BW approach against a control with no special training, the authors chose to compare BW to a control trained using a widely-taught process-writing approach $(P W)$. Rather than test null hypotheses that assert that $B W$ and $P W$ are equally effective for all students and that $B W$ and PW were equally effective with special-needs students and general education students, the authors decided to test two alternative hypotheses: 1) The BW intervention is significantly better than the PW intervention for all students. 2) Specialneeds students show significantly more improvement than general-education students for both interventions but special-needs students trained with BW show more improvement than those trained with $P W$.

The standardized Written Expression subtest of the Wechsler Individual Achievement Test II (WIAT-II), Form A, was used to quantify achievement. The WIAT was developed by Dr. David Wechsler and has been widely used to quantify academic achievement of people in many areas including written expression.

The BW and PW groups were tested using the WIAT before and after being trained to write for four months using the BW and PW approaches. Student growth was analyzed for general-education and special-needs students for each intervention. Highly significant results confirmed the hypotheses regarding the effectiveness of the BW approach.

The educational challenge to bring all children to higher levels of competence in their academics is daunting. In 2001, the No Child Left Behind Act (NCLB) was passed (www.nclb.gov) calling on educators to use research-validated strategies in order to effectively teach an ever-increasing diverse population of students. Elementary and middle schools across the nation are engaged in the pursuit of finding the best ways to teach the foundation skills of reading, writing, and arithmetic at a faster pace than ever before. Educators continue to deliberate which teaching strategies will improve student academic skills levels across the curriculum. School districts across the nation are seeking innovative research-based teaching strategies to improve student performance. 